\author{
SEDIGHE AZIMI $(*)$ - ESMAT MAHDIKHANI-MOGHADAM $(*)$ - HAMID ROUHANI $(*)$ \\ HAMID RAJABI MEMARI $(* *)$
}

\title{
DESCRIPTION OF TYLENCHORHYNCHUS IRANENSIS SP. N. (NEMATODA TELOTYLENCHIDAE) FROM IRAN
}

\author{
(*) Department of Plant Protection, College of Agriculture, Ferdowsi University of Mashhad, P.O. Box 91775-1163, \\ Mashhad, Iran. \\ (**) Department of Agronomy and Plant Breeding, College of Agriculture, Shahid Chamran University of Ahvaz, P.O. \\ Box 61357-83151, Ahvaz, Iran \\ Corresponding author: Esmat Mahdikhani-Moghadam, e-mail mahdikhani-e@ferdowsi.um.ac.ir
}

\begin{abstract}
Azimi S., Mahdikhani-Moghadam E., Rouhani H., Rajabi Memari H. - Description of Tylenchorhynchus iranensis sp.n. (Nematoda Telotylenchidae) from Iran.

A new species of stunt nematodes, Tylenchorhynchus iranensis sp. $\mathrm{n}$. is described from the rhizosphere of faba bean (Vicia faba L.), from material collected in the Khuzestan province, southwestern Iran. The new species is characterized by the following combination of features: lateral fields with four non areolated incisures, cephalic region continuous to slightly offset and conformed by 6-7 fine annuli, stylet 15-18 $\mu \mathrm{m}$ long, post-anal intestinal sac extends into the entire tail cavity, epiptygma present, tail sub-cylindrical with a hemispherical to sub-hemispherical smooth terminus, 46-65 $\mu \mathrm{m}$ long and composed by 46-49 annuli. Molecular analysis based on 28S rRNA gene sequences placed T. iranensis sp. n. within a clade that contained representatives of the genus Tylenchorhynchus with high support.
\end{abstract}

KEY WoRDS: 28S rRNA gene, morphology, new species, taxonomy, Tylenchorhynchus.

\section{INTRODUCTION}

The stunt nematodes are root surface tissue feeders, parasites of wide range of plant species in nature and are commonly found in vegetable fields, grasslands and forest soils (SIDDIQI, 2000). The cosmopolitan genus Tylenchorhynchus was established by Cobb in 1913 for $T$. cylindricus found in California, EE.UU. Hitherto, there are 133 valid species assigned to the genus Tylenchorhynchus (GERAERT, 2011). So far, 30 species of this genus have been reported from different regions of Iran (MIRBABAEI KARANI et al., 2015).

There have been several attempts to classify the stunt nematodes into different genera using various morphological characters. ForTuNER and LUC (1987), SIDDIQI (2000) and Geraert (2011) are three classifications that currently most widely used for them (HANDOO et al., 2014).

The genus Tylenchorhynchus is very similar to the genus Bitylenchus Filipjev, 1934. Bitylenchus is differentiated from Tylenchorhynchus in having areolated outer bands of lateral fields, a large postanal intestinal sac containing intestinal granules and fasciculi, relatively more thickened cuticle at the female tail tip, and gubernaculum lacking a crest (GOMEZ-BARCINA et al., 1992). These characters are recorded in several species belonging to both Tylenchorhyncus and Bitylenchus (HANDOO, 2000). Many workers consider these to be secondary characteristics and consequently place Bitylenchus as a junior synonym of Tylenchorhynchus (ForTUNER and LUC, 1987; HANDOO, 2000; GERAERT, 2011). This action is not widely accepted and other workers recognizing both as valid genera (SIDDIQI, 2000; ANDRASSY, 2007; HANDOO et al., 2014; GHADERI et al., 2014).
The genus Tylenchorhynchus is similar in morphology to the genus Paratrophurus Arias, 1970 however Paratrophurus differs from Tylenchorhynchus in having smooth labial region, conoid-rounded and abnormally thickened terminal cuticle of the tail (SIDDIQI, 2000). As $P$. striatus Castillo, Siddiqi \& Gomez-Barcina, 1989 is described as having a striated lip region, and certain species of Tylenchorhynchus are reported as having a more thickened terminal cuticle and smooth labial region (such as T. parasudanensis Elbadri, Moon, Lee \& Choo, 2010), discrimination of species assigned to these genera may become increasingly difficult.

To date, no molecular data have been published for many of Bitylenchus, Paratrophurus and Tylenchorhynchus species. In study by GHADERI et al., (2014), phylogenetic relationships of Telotylenchidae Siddiqi, 1960 were evaluated using sequencing of the D2D3 expansion fragments of the $28 \mathrm{~S}$ rRNA gene. In the phylogenetic tree, the representatives of Tylenchorhynchus and Bitylenchus formed two separate clades.

Recently, Handoo et al., (2014), performed an integrative taxonomy of the genera Bitylenchus, Paratrophurus and Tylenchorhynchus. Five species of the genus Bitylenchus, three species of the genus Paratrophurus and nine species of the genus Tylenchorhynchus were molecularly characterized. The species of the genera Tylenchorhynchus and Bitylenchus clustered separately in most trees. Also, in both $28 \mathrm{~S}$ and $18 \mathrm{~S}$ trees, representatives of the genera Telotylenchus Siddiqi, 1960 and Paratrophurus were nested within Tylenchorhynchus and Bitylenchus, respectively. Thus, additional molecular data are needed to clarify the phylogenetic relationships of these genera. In this study 
we described a new stunt nematode species found in association with faba bean in Iran.

\section{MATERIALS AND METHODS}

\section{Nematode Samples}

Soil samples were collected from the rhizosphere of faba bean (Vicia faba L.) fields in the vicinity of Dizful city in Khuzestan Province, south-western Iran. Nematodes were extracted from soil samples by using centrifugal flotation technique (JENKINS, 1964). The collected specimens were killed in hot $4 \%$ formaldehyde solution and transferred to anhydrous glycerin according to De Grisse's (1969). Nematodes were mounted in a small drop of glycerin on permanent slides. Observations and measurements were carried out using a Leitz SMLUX light microscope equipped with drawing tube. Some of the best-preserved specimens were photographed using an Olympus DP72 digital camera attached to an Olympus BX51 light microscope. Nematode species were identified based on morphological and morphometric characters (HANDOO, 2000; Geraert, 2011).

\section{Dna eXtracting, PCR AND SEQUencing}

For molecular analyses, a single female individual of the new species was picked out from samples, examined in a temporary slide under the light microscope, transferred to 7 $\mu \mathrm{l}$ of AE buffer (10 mM Tris-Cl, $0.5 \mathrm{mM}$ EDTA; pH 9.0) on a clean slide and then crushed using a cover slip. The suspension was collected by adding $20 \mu \mathrm{l} \mathrm{AE}$ buffer. Each DNA sample was stored at $-20^{\circ} \mathrm{C}$ until used as a PCR template (PEDRAM et al., 2011). The D2-D3 expansion segment of the 28S rDNA was amplified using the forward D2A (5'-ACAAGTACCGTGAGGGAAAGTTG-3') and reverse D3B (5'-TCGGAAGGAACCAGCTACTA-3') primers (NUNN, 1992). PCR reactions of $25 \mu \mathrm{l}$ were made with $14 \mu \mathrm{l}$ of distilled water, $2.5 \mu \mathrm{l}$ of $10 \times$ PCR buffer, 0.5 $\mu \mathrm{l}$ of dNTP mixture, $1.5 \mu \mathrm{l}$ of $50 \mathrm{mM} \mathrm{MgCl} 2,1 \mu \mathrm{l}$ of each primer $(10 \mathrm{pmol} / \mu \mathrm{l}), 0.5 \mu \mathrm{l}$ of Taq polymerase (CinnaGen, Tehran, Iran, c. $5 \mathrm{U} / \mu \mathrm{l})$, and $4 \mu \mathrm{l}$ of DNA template. The thermal cycling program was as follows: initial denaturation at $95^{\circ} \mathrm{C}$ for $6 \mathrm{~min}$, followed by 35 cycles of denaturation at $94^{\circ} \mathrm{C}$ for $30 \mathrm{~s}$, annealing at $55^{\circ} \mathrm{C}$ for $30 \mathrm{~s}$ and extension at $72^{\circ} \mathrm{C}$ for $1 \mathrm{~min}$. A final extension was performed at $72^{\circ} \mathrm{C}$ for 10 min (PEDRAM et al., 2011). Amplification success was evaluated electrophoretically on $1 \%$ agarose gel. The PCR products were purified using the QIAquick PCR purification kit (Qiagen $\AA$ ) following the manufacturer's protocol and sequenced directly using the PCR primers with an ABI 3730XL sequencer (Bioneer Corporation, South Korea). The newly obtained sequences were deposited into the GenBank database (accession numbers KU248449 and KU248450).

\section{Phylogenetic Analyses}

The newly obtained sequences of the D2D3 fragments of $28 \mathrm{~S}$ rDNA and additional sequences of relevant taxa selected after a BlastN search, were aligned by Clustal X2 (http://www.clustal.org/) using the default parameters. The outgroup taxa were chosen according to a previous study (HANDOO et al., 2014). Model of base substitution was selected using Mr Model test 2 (NyLANDER, 2004), and based on the Akaike criteria. A general time reversible model, including among-site rate heterogeneity and estimates of invariant sites $(\mathrm{GTR}+\mathrm{G}+\mathrm{I})$, was selected for the phylogenetic analyses. Bayesian analysis was used to infer the phylogenetic tree on MrBayes v3.1.2 (RONQUIST \& HUELSENBECK, 2003), running the chain for one million generations. After discarding burn-in samples and evaluating convergence, the remaining samples were retained for further analyses. The Markov chain Monte Carlo (MCMC) method within a Bayesian framework was used to determine equilibrium distribution and help estimate the posterior probabilities of the phylogenetic tree (LARGET \& SimON, 1999) using the 50\% majority rule. The Bayesian posterior probabilities (BPP) higher than 50\% were given on appropriate clades. The output file of the phylogenetic program was visualized using Dendroscope V.3.2.8 (HuSON \& SCORNAVACCA, 2012) and re-drawn in CorelDRAW software version 12.

\section{RESULTS AND DISCUSSION}

Tylenchorhynchus iranensis $\mathrm{sp} . \mathrm{n}$. (Figs I and II)

Measurements: Table 1.

\section{DESCRIPTION}

FEMALE - Body straight to slightly arcuate ventrally following heat fixation. Cuticle annuli 1-1.4 $\mu \mathrm{m}$ wide at mid-body. Lateral field slightly more than one-fourth of maximum body diameter, composed of four incisures along the body, including tail region, with non-areolated bands; cephalic region hemispherical, bearing 6-7 fine annuli, continuous to slightly offset from body, $6.5-7 \mu \mathrm{m}$ wide, 3-4 $\mu \mathrm{m}$ high; cephalic framework lightly sclerotized. Stylet knobs rounded, slightly posteriorly directed, 3.6-4 $\mu \mathrm{m}$ across. Dorsal gland orifice at 3-4.5 $\mu \mathrm{m}$ behind to stylet knobs. Metacorpus oval, 18-20 $\mu \mathrm{m}$ long and 13.5-15 $\mu \mathrm{m}$ wide. Deirids absent. Basal pharyngeal bulb pyriform, 30-35 $\mu \mathrm{m}$ long and 14-17.5 $\mu \mathrm{m}$ wide, offset from intestine. Postanal intestinal sac extending into the entire tail cavity and containing intestinal granules and fasciculi. Reproductive system didelphic-amphidelphic, vagina 9-11 $\mu \mathrm{m}$ long, slightly less than half of vulval body width, with a small cavity and epiptygma; vulva with minute cuticular flaps; spermatheca oval, filled with rounded sperm, 37-44 $\mu \mathrm{m}$ long and 14-16 $\mu \mathrm{m}$ wide. Tail sub-cylindrical with a hemispherical to sub-hemispherical, smooth terminus, bearing 46-49 annuli on ventral side; hyaline portion 4.5-8 $\mu \mathrm{m}$, about $9.5-12.5 \%$ of tail length. Phasmids located at middle of tail.

MALE - General morphology similar to that of female except for character states associated with sexual differences. Tail conoid and pointed, enveloped by bursa with crenate edges. Spicules 21-30 $\mu \mathrm{m}$ long, slightly curved ventrally and flanged distally. Gubernaculum protrusible, $11-15 \mu \mathrm{m}$ long and slightly curved proximally.

\section{TYPE HOST AND LOCALITY}

Soil samples collected from the rhizosphere of faba bean (Vicia faba L.) in the vicinity of Dizful city in Khuzestan Province, GPS coordinates: $32^{\circ} 20^{\prime} \mathrm{N}, 48^{\circ} 30^{\prime} \mathrm{E}$, southwestern Iran.

\section{ETYMOLOGY}

The new species name refers to the country name where it was found.

\section{Type Material}

Holotype, 20 females and 17 males paratypes deposited at the nematology laboratory of the Department of Plant 


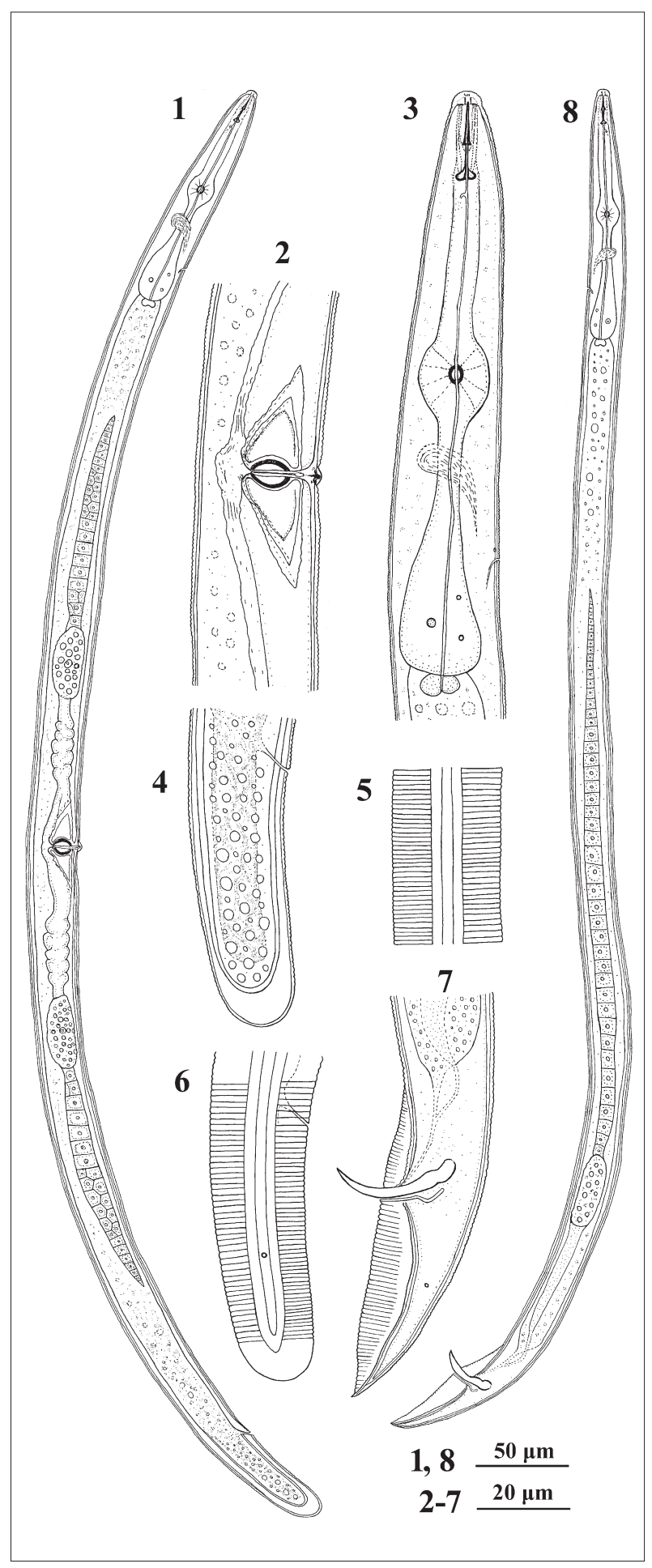

Fig. I - Tylenchorhynchus iranensis sp. n. 1-6: Female. 1. Entire Body; 2. Vulval region; 3. Anterior region; 4. Tail; 5. Lateral field at mid-body; 6 . Tail showing phasmids. Male. 7. Tail; 8 . Entire body.

Protection, Shahid Chamran University of Ahvaz, Ahvaz, Iran. Two females and one male paratypes deposited at the nematology laboratory of the Department of Plant Protection, Ferdowsi University of Mashhad, Mashhad, Iran. Two females and two males paratypes deposited at the Wageningen Nematode Collection (WaNeCo), Wageningen, The Netherlands (collection number: WT 3667).

\section{DiAGNOSIS}

Tylenchorhynchus iranensis sp. $\mathrm{n}$. is characterized by lateral fields composed of four incisures, with nonareolated bands, cephalic region with 6-7 fine annuli, post-anal intestinal sac extending into the entire tail cavity, epiptygma and minute vulval flaps present and a smooth tail terminus.

\section{RELATIONSHIPS}

The new species comes close to T. brevilineatus Williams, 1960, T. crassicaudatus Williams, 1960, T. mediocris (Talavera \& Siddiqi, 1995) Brzeski \& Dolinski, 1998, T. goffarti, Sturhan 1966 and T. teeni Hashim, 1984. Compared to $T$. brevilineatus, the lip region of the new species is continuous to slightly offset from the body ( $v s$ lip region set off from the body by a deep constriction), the outer bands of the lateral fields smooth (vs distinctly crenate), without longitudinal lines ( $v s$ longitudinal lines are present on the anterior end of the body), maximum body width is greater $(23.5-28 v s 16-19 \mu \mathrm{m})$, the width of stylet knobs are greater ( $4 v s 2.5 \mu \mathrm{m})$, a wider range of the dorsal gland orifice (3-4.5 vs 1-2.5 $\mu \mathrm{m})$, spermatheca oval ( $v s$ rounded) and tail sub-cylindrical with a hemispherical to sub-hemispherical terminus ( $v s$ tail conoid, tapering to a bluntly rounded terminus).

Compared to T. crassicaudatus, cuticle annuli of the new species 1-1.4 $\mu \mathrm{m}$ wide at mid-body ( $v s$ cuticle coarsely annulated, annuli about $2 \mu \mathrm{m}$ on middle of body), the bands of the lateral fields smooth (vs outer lines crenate), cephalic region bearing 6-7 annuli ( $v s$ apparently 3 annuli), stylet is shorter (15-18 vs 20-23 $\mu \mathrm{m})$ and higher number of tail annuli (46-49 vs 13-24).

Compared to $T$. goffarti, the new species has a longer body (813-873 vs 490-700 $\mu \mathrm{m}$ after HANDOO, 2000), maximum body width is greater (23.5-28 vs $19 \mu \mathrm{m})$, the lip region is continuous to slightly offset from the body ( $v s$ lip region set off by constriction), the outer bands of the lateral fields smooth (vs outer lines of the lateral fields areolated), stylet is longer (15-18 vs 13-15 $\mu \mathrm{m})$, a wider range of the dorsal gland orifice $(3-4.5 \nu s<2 \mu \mathrm{m})$, basal pharyngeal bulb offset from intestine ( $v s$ slightly overlapping intestine), spermatheca oval (vs rounded) and tail 46-65 $\mu \mathrm{m}$ long ( $v s 36 \mu \mathrm{m}$ long).

Compared to T. mediocris, the bands of the lateral fields are smooth in the new species ( $v s$ outer lines irregularly areolated), phasmids located at middle of tail ( $v s$ phasmids located in the anterior half of the tail), spicule and gubernaculum lengths are longer (21-30 vs 18-20.5 $\mu \mathrm{m}$ and 11-15 vs 9.5-11 $\mu \mathrm{m}$ respectively) and epiptygma present ( $v s$ absent).

Compared to T. teeni, the body is straight to slightly arcuate ventrally after fixation in the new species, while the body in $T$. teeni is ventrally arcuate to almost spiral after fixation. Outer incisures of the lateral fields in the new species are smooth ( $v s$ crenate), maximum body width is greater $(23.5-28 v s 18-23 \mu \mathrm{m})$, the width of stylet knobs are greater ( 4 vs 2.5-3 $\mu \mathrm{m})$, spermatheca is oval with rounded sperm but in $T$. teeni, the spermatheca are round with ovoid to elongate sperm. Also, the tail terminus is annulated in T. teeni.

\section{MoleCUlar PHYLOGENETIC STATUS}

The alignment of the D2D3 expansion fragments of 28S rRNA gene sequences of 39 taxa (including two out group taxa), yielded a data set with 745 characters. The phylogenetic relationships between the new species and representatives of Telotylenchidae, as inferred from the BI 


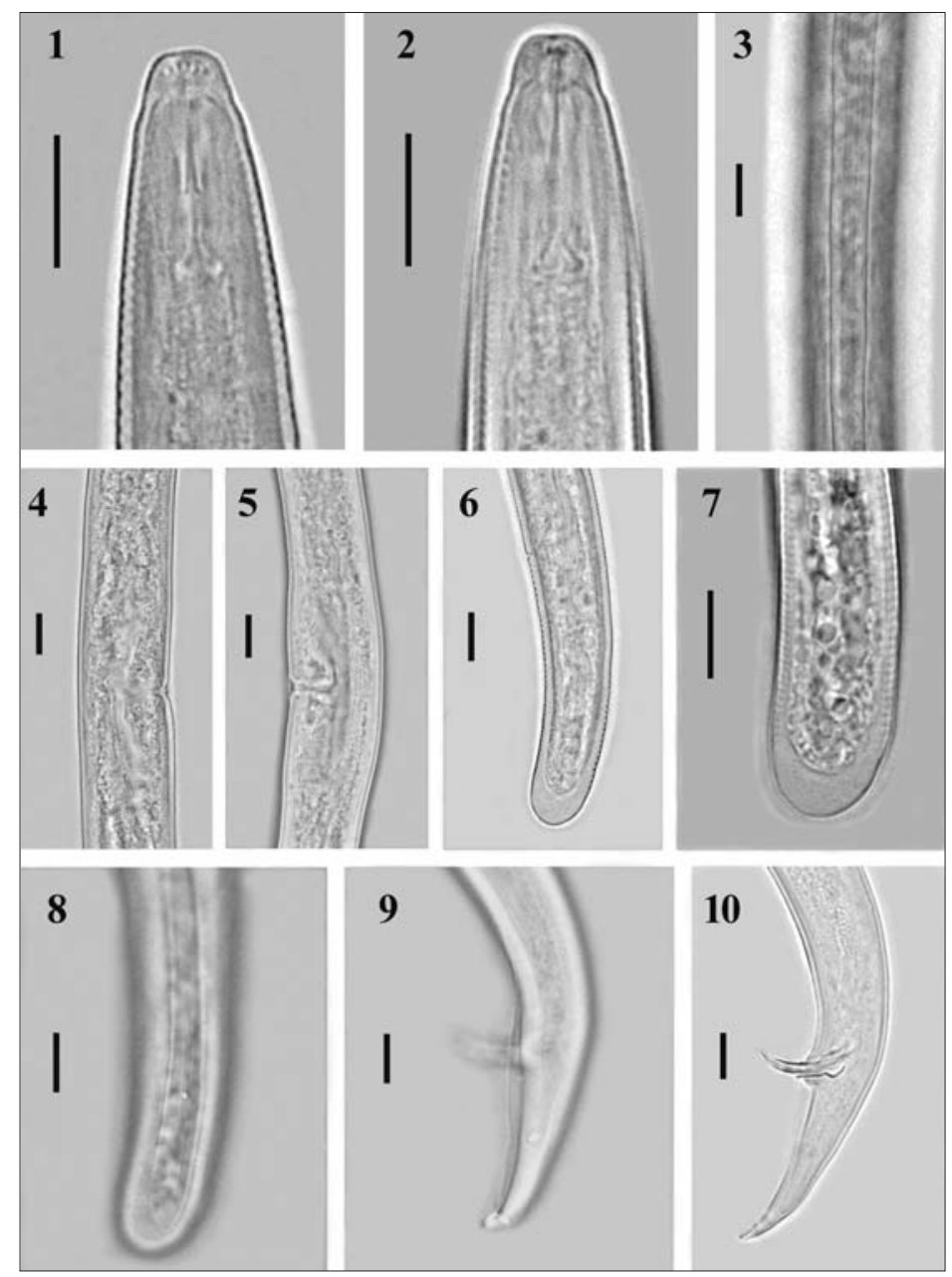

Fig. II - Tylenchorhynchus iranensis sp. n. Female. 1. Anterior end; 3. Lateral field at mid-body; 4, 5. Vulval region; 6, 7. Tail; 8. Tail showing phasmids. Male. 2. Anterior end; 9. Tail showing phasmids; 10. Tail. (Scale bars $=10 \mu \mathrm{m}$.).

Table 1 - Morphometrics of Tylenchorhynchus iranensis sp. $\mathrm{n}$. All measurements are in $\mu \mathrm{m}$ and in the form: mean \pm s.d. (range).

\begin{tabular}{|c|c|c|c|}
\hline $\begin{array}{c}\text { Paratypes } \\
\text { Males }\end{array}$ & $\begin{array}{c}\text { Paratypes } \\
\text { Females }\end{array}$ & $\begin{array}{l}\text { Holotype } \\
\text { Females }\end{array}$ & Character \\
\hline 20 & 24 & 1 & $\mathrm{n}$ \\
\hline $767.4 \pm 30.9(719.0-810.0)$ & $836.4 \pm 23.2(813.0-873.0)$ & 851.2 & $\mathrm{~L}$ \\
\hline $31.9 \pm 1.6(30.0-34.0)$ & $31.3 \pm 1.6(29.0-33.2)$ & 29.6 & $\mathrm{a}$ \\
\hline $5.9 \pm 0.6(5.5-6.9)$ & $6 \pm 0.4(5.6-6.8)$ & 6.5 & $\mathrm{~b}$ \\
\hline $14.5 \pm 0.7(14.0-16.0)$ & $13.2 \pm 0.8(12.5-15.0)$ & 14.8 & $\mathrm{c}$ \\
\hline $2.9 \pm 0.3(2.5-3.4)$ & $3.1 \pm 0.5(2.5-3.7)$ & 2.7 & $\mathrm{c}^{\prime}$ \\
\hline- & $53.5 \pm 1.6(51.8-56.9)$ & 52.0 & $\mathrm{~V}$ \\
\hline- & $58.1 \pm 2.1(55.0-62.9)$ & 55.9 & $\mathrm{~V}^{\prime}$ \\
\hline $17.0 \pm 1.0(15.0-18.0)$ & $17.1 \pm 1.0(15.0-18.0)$ & 17.4 & Stylet length \\
\hline $53.9 \pm 3.9(47.0-62.0)$ & $54.0 \pm 3.5(46.0-60.0)$ & 53.1 & $\mathrm{~m}$ \\
\hline $3.1 \pm 0.1(2.7-3.3)$ & $3.8 \pm 0.4(3.3-4.5)$ & 3.4 & DGO \\
\hline $51.2 \pm 1.5(48.0-54.0)$ & $50.3 \pm 2.6(47.0-54.0)$ & 48.3 & $\mathrm{MB}$ \\
\hline $24.0 \pm 1.4(23.5-26.0)$ & $25.4 \pm 2.0(23.5-28.0)$ & 24.2 & Body width \\
\hline $98.7 \pm 8.4(89.6-115.0)$ & $102.3 \pm 8.7(93.0-125.0)$ & 105.5 & Anterior end to excretory pore \\
\hline- & $24.7 \pm 2.2(21.4-29.0)$ & 27.1 & Vulval body width \\
\hline $16.7 \pm 1.4(14.5-19.0)$ & $19.3 \pm 2.3(16.0-24.0)$ & 21.2 & Anal body width \\
\hline $51.0 \pm 2.1(48.0-54.0)$ & $54.7 \pm 4.1(46.6-65.0)$ & 57.0 & Tail length \\
\hline $25.7 \pm 3.0(21.2-30.0)$ & - & - & Spicule length \\
\hline $12.6 \pm 1.3(11.0-15.0)$ & - & - & Gubernaculum length \\
\hline $56.8 \pm 9.3(48.0-71.0)$ & - & - & Bursa length \\
\hline- & $47.1 \pm 1.1(46.0-49.0)$ & 48 & Tail annuli \\
\hline
\end{tabular}


analysis, are presented in Figure III. Two major clades with high branch support values were distinguished in present phylogenetic tree. Clade I comprised eleven Tylenchorhynchus species and one Telotylenchus species. Clade II contained representatives of the genera Tylenchorhynchus, Bitylenchus, Macrotrophurus and Paratrophurus. The new species is placed with representatives of the genus Tylenchorhynchus with high support (92 BPP). There were no nucleotide differences between two sequences of the new species in this study.

In study by GHADERI et al., (2014) based on 28S rRNA gene, the representatives of Tylenchorhynchus and Bitylenchus formed two separate clades. This molecular phylogenetic study was conducted by only two species of Bitylenchus including B. dubius (Bütschli, 1873) Filipjev, 1936 and B. parvus Allen, 1955, which are similar in morphology.

The results of phylogenetic analyses based on $28 \mathrm{~S}$ rRNA gene by HANDOO et al., 2014 showed the monophyly for the genus Tylenchorhynchus sensu Siddiqi (2000) although eight species of Tylenchorhynchus and one species of Telotylenchus clustered in a clade but Tylenchorhynchus mediterraneus Handoo, PalomaresRius, Cantalapiedra-Navarrete, Liébanas, Subbotin and Castillo, 2014, formed another clade. In the phylogenetic tree based on $18 \mathrm{~S}$ rRNA gene, T. mediterraneus and

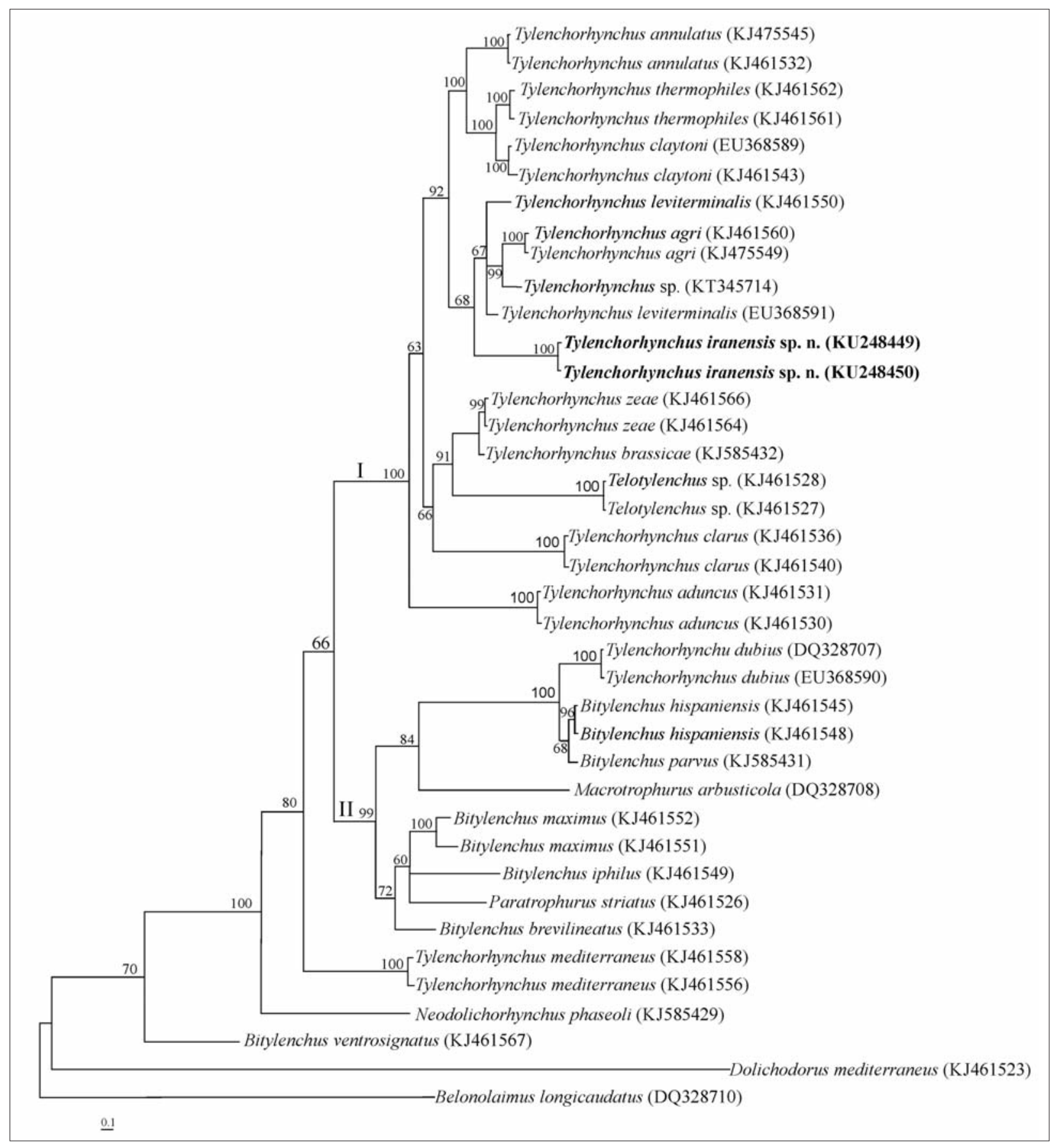

Fig. III - Bayesian 50\% majority rule consensus tree inferred from analysis of the D2-D3 domains of the 28S rRNA gene under the GTR $+\mathrm{G}+\mathrm{I}$ model. Bayesian posterior probability values more than $50 \%$ are given for appropriate clades. New sequences are indicated in bold. 
Telotylenchus ventralis Loof, 1963, arranged in a clade at considerable distance from other Tylenchorhynchus species. Also, in the phylogenetic tree based on ITS rRNA gene, seven sequences of $T$. mediterraneus clustered in a separate clade at considerable distance from other Tylenchorhynchus species. The hypothesis of monophyly for the genus Bitylenchus sensu Gómez-Barcina et al., (1992) and Siddiqi (2000) was accepted only after the exclusion of $B$. ventrosignatus (Tobar-Jiménez, 1969) Jairajpuri, 1982 from this genus. In the phylogenetic trees, Paratrophurus species clustered with Bitylenchus and confirmed close relationships between these genera.

The biodiversity of the family Telotylenchidae is still not fully clarified and requires further investigations (Handoo et al., 2014). Currently, a limited number of species of the genera Bitylenchus, Paratrophurus and Tylenchorhynchus has been sequenced. As a result, in order to clarify the relationships among species of these genera, a more comprehensive phylogenetic study is needed, in particular on all available species of these genera from different geographical origins.

\section{ACKNOWLEDGMENTS}

We gratefully thank Dr. Majid Pedram (Tarbiat Modares University, Iran) and Dr. Reza Ghaderi (Shiraz University, Iran) for their helps and valuable comments. The authors also appreciate the kind help of En. Yousef Panahandeh (Tarbiat Modares University, Iran).

\section{REFERENCES}

ANDRASSY I., 2007 - Free-living nematodes of Hungary (Nematoda errantia). Vol. II. (Series Eds: Csuzdi C, Mahunka S). Budapest, Hungary, Hungarian Natural History Museum and Systematic Zoology Research Group of the Hungarian Academy of Sciences, 503 pp.

ARIAS M., 1970 - Paratrophurus loofi n. gen., n. sp. (Tylenchidae), from Spain. - Nematologica, 16: 47-50.

Castillo P., SiddiQi M.R., Gomez-Barcina A., 1989 Studies on the genus Paratrophurus Arias (Nematoda: Tylenchina) with descriptions of two new species.Nematol. medit., 17: 83-95.

DE GRISSE A.T., 1969 - Redescription and modification of some techniques used in the study of nematodes phytoparasitaires. - Meded. Rijks. Landb. Wetensch. Gent, 34: 351-369.

Elbadri G.A.A., Moon I.S., LeE D.W., Choo H.J., 2010 -
Two new species of Tylenchorhynchus Cobb, 1913 (Nematoda: Belonolaimidae) from Sudan. - Korean Journal of applied Entomology, 49: 57-60.

FORTUNER R., LUC M., 1987 - A reappraisal of Tylenchina (Nemata). 6. The family Belonolaimidae Whitehead, 1960. - Revue de Nématol., 10: 183-202.

GERAERT E., 2011 - The Dolichodoridae of the world. Identification of the family Dolichodoridae. Ghent, Belgium, Academia Press, 520 pp.

Ghaderi R., Karegar A., Niknam G., Subbotin S.A., 2014 - Phylogenetic relationships of Telotylenchidae Siddiqi, 1960 and Merliniidae Siddiqi, 1971 (Nematoda: Tylenchida) from Iran, as inferred from the analysis of the D2D3 expansion fragments of $28 S$ rRNA gene sequences. - Nematology, 16: 863-877.

Gomez-Barcina A., Siddidi M.R., Castillo P., 1992 - The genus Bitylenchus Filipjev, 1934 (Nematoda: Tylenchida) with descriptions of two new species from Spain. - J. Helminth. Soc. Wash., 59: 96-110.

HANDOO Z.A., $2000-A$ key and diagnostic compendium to the species of the genus Tylenchorhynchus Cobb, 1913 (Nematoda: Belonolaimidae). - J. Nematol., 32: 20-34.

Handoo Z.A., Palomares-Rius J.E., CantalapiedraNavarrete C., Liebanas G, Subbbotin S.A., Castillo P., 2014 - Integrative taxonomy of the stunt nematodes of the genera Bitylenchus and Tylenchorhynchus (Nematoda, Telotylenchidae) with description of two new species and a molecular phylogeny. - Zool. J. Linn. Soc., 172: 231-264.

HASHIM Z., 1984 - Description of Tylenchorhynchus teeni n. sp. and observations on Rotylenchus cypriensis Antoniou, 1980 (Nematoda: Tylenchida) from Jordan. Syst. Parasitol., 6: 33-38.

JENKINS W.R., 1964 - A rapid centrifugal flotation technique for separating nematodes from soil. - Pl. Dis. Reptr., 48: 692.

Mirbabaei Karani S.H., Kashi L., GHAderi R., KaREgaR A., 2015 - Five Species of Tylenchidae and Dolichodoridae (Nematoda: Tylenchoidea) from Iran. - J. Agr. Sci. Tech., 15: 227-240.

NunN G.B., 1992 - Nematode molecular evolution. PhD Thesis, University of Nottingham, Nottingham, U.K., 192 pp.

SIDDIQI M.R., 1960 - Telotylenchus, a new nematode genus from North India (Tylenchida Telotylenchinae n. subfam.). - Nematologica, 5: 73-77.

SIDDIQI M.R., 2000 - Tylenchida parasites of plants and insects. 2nd edition. Wallingford, UK. CABI Publishing., $833 \mathrm{pp}$. 